\title{
The Cultural and School Related Causes of Primary School Dropout among Girls in
}

\section{District Jaffarabad}

\author{
Shakeel Ahmed ${ }^{1}$, Ifthikhar Shafiq ${ }^{2}$ \& Abdul Nasir Kiazai ${ }^{3}$ \\ ${ }^{1}$ Lectures Department of Sociology, ${ }^{2}$.M: Phil Scholar \\ $\&{ }^{3}$ Director, (IER) Institute of Education \& Research
}

\begin{abstract}
The aim of the study was to find out the causes of primary school dropout among girls in district Jaffarabad. The data was amassed through the aid of the close ended questionnaires specially designed for teachers, dropped out girls, and their parents. A sample of 150People was chosen by using stratified random sampling technique. The amassed data was tabulated and analyse by using simple percentage method. The study explored the causes of school dropouts by documenting the opinions of the teachers, dropped out students and their parents. The respondents displayed disparate opinions concerning girls' dropout at primary level. They contemplated that area gives less importance to girls' education. Gender disparity, linguistic related problems, custom of early marriage, cultural and religious beliefs influence of tribal leadership, untrained teachers and corporal punishment were also reported as major causes of school dropout. The findings of the study will be helpful for the government, parents and teachers to take measures in order to control high dropout rate and increase enrolment rate at primary level of schooling.
\end{abstract}

Keywords: Drop out, Education, Languages, Achievements

\section{Introduction}

Education is not merely an excellent way to accomplish countless triumphant aims but additionally access to destination. Education is the light which enlightens the way of life and it is also one of the strongest tools for lessening inequity. The object of education is to prepare the 
young to educate themselves throughout their lives. Education, in fact,is a debt due from present to future generation. An education system is the key to progress and development. It serves as the foundation upon which the infrastructure of various agencies of a state is built. Education is one of the basic tools of social and economic development of a nation.

In the word of Golda "The purpose of education is to civilize the thousands of barbarians that are born in to this world every hour". Failing in bringing change in learner undermines the worth of education. Education is the most important tool of bringing changes in man. Education, on the one hand, acculturates new born and, on the other hand, is the major source of transmitting culture and language from one generation to the next. Culture and education are interdependent and their relationship is inseparable.

The importance of culture in man's life cannot be denied. Education of different elements of culture such as language, norms, values and customs and traditions helps men in adaptation to the natural and social environment. Education in culture is transmitted by the family, schools and society. The problems related to education directly affect the development of culture and language.

Building a good education system provides a solid basis in the shape of quality primary education. Education has been a priority of the governments of Pakistan. The country had ten years Development Plan (2001-2011) aimed at broad based socio-economic development. The National Action Plan (2001-2015) was made across colossal established consultations alongside the main stakeholders of EFA. The main objective for arranging this plan was the 6th EFA goal which aims at facilitating poor populace clusters in rural area and alongside focused on out of school and illiterate girls and woman and improving quality of education through enhancing learning achievements of the children.

Education system in Pakistan is characterized by low literacy, acute shortage of teaching staff, low enrolment and high dropout rate. According to a report published by The Department of International Relation, Government of Pakistan, the dropout rate in Pakistan was 35\% in 2010 
which was very high as compared to other South Asian Countries. The Literacy rate in Pakistan is said to be $56 \%$ but the validity of this figure is yet to confirm because it also includes all those people who can just write their names. Pakistan stands at the $113^{\text {th }}$ position among 120 countries. The reasons for the deteriorated condition of educational system in Pakistan are various but the most important ones are low enrolment and high rate of dropout at primary level. Various scholars have defined the term 'Dropout' differently. According to Jamil et.al, (2010) dropout is "a term used for the children, who for any reason other than death, discontinue schooling and leave their education uncompleted". Although the government of Pakistan has taken many initiatives such as placement of graduate teachers at primary level, revision of old curricula, production of text books, and scholarships to poor girl students, but we have not achieved the target of $100 \%$ enrolment rate at primary level that is the main aim of National Action Plan". (Government of Pakistan, 2005) The same target was set for the underdeveloped nations under 'Millennium Development Goal “(2004), its goal '2' is tomake it possible that by 2015 every boy and girl would be capable of completing primary education. The target of making primary education Universalize seems difficult to accomplish as the majority of school going children are out of school.

Pakistan has gained remarkable achievement in increasing adult literacy. However, the target of Universalization of basic education remains unachieved because of low participation of students and a high rate of dropout. Despite many rounds of The Nation Plan of Action during the nineties a solid basis for sustained enrolment of students could not be achieved. The high rate of dropout at primary levels remains a cause of great concern.(Bilquees \& Saqib, 2004)

According to countless indicators cluster survey 2010, net completion rate is at $56 \%$ on the finished basis alongside a higher completion rate in boys at $59.4 \%$ than girls at $51.3 \%$ and additionally higher completion rate in metropolis students at $67.3 \%$ than those from rural span at $52.7 \%$. 
Balochistan comprised of $44 \%$ of land and only $5 \%$ of Pakistan's population. Balochistan, on account of its culture and tribal system, differs from the rest of the provinces. The people of Balochistan have their own ethnic identity and resist changes in their cultural values. This is an undeniable fact that women are given less importance when it comes to the right of education. In Balochistan the education of women is at its lower point because of the countless factors that retain it low. Firstly, Gender disparity exists in all walks of life and women are not allowed to get education due to the pressure of tribal leadership.

Secondly, the medium of language has been a matter of great concern. The students belonging to Baloch, Pashtoon and Sindhi speaking families face problems when education is imparted in the National language, Urdu.

Thirdly, the custom of early marriage exists in our society. IN rural areas parents consider girls' education as of no benefit when they leave their own family after getting married.

Fourthly, it has been found that in our society some cultural and religious beliefs constrain girls from making their decision and expressing their opinions regarding their right to education.

Fifthly, the narrow -mindedness of people come to be their daughter out of schools.

Sixthly, poverty compels the parents to be incapable of sending their children to school.

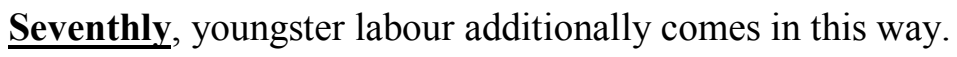

Eighthly, the radicalism, as the last eight years, making the schools targeted due to that people are horrified to dispatch their children to schools. Ninthly, the teachers' absenteeism that is vital and worth able cause of dropping out of girls in the schools.

Jaffarabad district is one of the most populated districts of Balochistan where people belonging to different ethnic groups (Baloch, Sindhi,Pashtoon) are living to gather. The area is facing problems of different nature. One of the serious problems is high rate of school dropout. According to school census report 2014-15Published by Balochistan Education Management Information System (BEMIS), the dropout rate among female students in the area is $47 \%$. This figure is quite alarming and requires immediate solutions. 


\section{Methodology}

The study was delineated to government girls' primary schools of jaffarabad district. The population of the study comprised of all female teachers of the government primary schools, the dropped out students(girls) and their parents belonging to different communities (Baloch, Sindhi and Pashtoon). A sample of 150 people (50 teachers, 50 parents and 50 dropped out girls) was chosen by using the stratified random sampling technique.

The data was collected with the help of close ended questionnaires especially designed for the teachers, the dropped out students and their parents. The respondents were given three options to reply. The gathered data was tabulated and analysed by using simple percentage method.

\section{Findings and discussion}

\section{The causes of dropout as perceived by the parents}

The high rate of dropout among female students is a serious threat to our education system. To explore the causes of the problem, the opinions of the parents were gathered.

\section{Causes of dropout: The Parents 'Opinions}

\begin{tabular}{|cll|}
\hline S.No & Parents' opinions & $\begin{array}{c}\text { Responses } \\
\text { (In Percent) }\end{array}$ \\
1. & Gender discrimination & 50 \\
2. & Untrained Teachers & 30 \\
3. & Over loaded syllabus & 20 \\
4. & Language related problem & 20 \\
5. & Lack of child's interest in education & 30 \\
6. & Corporal punishment & 35 \\
7. & Role of teachers' association & 35 \\
8. & Early Marriage & 35 \\
9. & Cultural and Religious beliefs & 40 \\
\hline
\end{tabular}

The above table shows the causes of high dropout among the girls.

This is clearly obvious that gender disparity (giving priority to male children over female children) is the main cause of school dropout among female students. 
The other major causes were the role of teachers' association, corporal punishment, Lack of child's interest in education over loaded syllabus, early marriage, and cultural and religious beliefs.

20 percent respondents believe that language was a major cause of school dropout. Students belonging to Balochi, Brahui, Sindhi, and Pashto speaking families cannot understand Urdu properly and hence leave school without completing primary education. Thirty five percent (35\%) respondents were of the view that the custom of early marriage is the cause of school dropout while $40 \%$ agreed that some cultural and religious beliefs constrain girls from getting education.

\section{The reasons for drop out: Teachers' Responses}

The teachers' perception regarding dropouts was very significant as it would be useful to make policies. Teachers have close interaction with children as they spend a lot of time in school with them.

The causes of dropout: Teachers' Responses.

\begin{tabular}{|rll|}
\hline S.No. & Teachers' views & $\begin{array}{c}\text { Responses } \\
\text { (In Percent) }\end{array}$ \\
1. & School environment & 20 \\
2. & Medium of learning (Language) & 35 \\
3. & Parents' illiteracy & 26 \\
4. & Giving low priority to girls' education & 30 \\
5. & Media & 15 \\
6. & Overloaded syllabus & 35 \\
7. & Early marriage & 45 \\
8. & Cultural and religious beliefs & 40 \\
\hline
\end{tabular}

The above table shows the opinions of the teachers regarding the issue of school dropout. The basic cause identified by the teachers was the lack of parents' interest in girls' education. It has been observed that parents give low priority to girls' education. This rectifies that gender 
disparity exists in the area and the family has no interest in sending their female children to schools. Another important cause which teachers identified was the medium of learning .Students belonging to non-Urdu- speaking families face the problem of language. They cannot understand Urdu properly and as a result lose interest in education and leave school without completing education.

Over loaded syllabus, media, illiteracy of parents were also the causes of high rate of dropout identified by the teachers. According to Teachers opinions the early marriage custom and some cultural and religious beliefs also constrain girls from getting education. .

\section{The reasons for drop out: Girls 'Opinions.}

The students are the main element of any education system and that is why they are the principle element of this study. The students are the direct victims of this problem. Their opinions regarding school dropout are of great importance for the study.

The table given below shows the views of the dropped out girls.

\begin{tabular}{||lll|}
\hline No & Girls 'opinions. & $\begin{array}{l}\text { Responses } \\
\text { (In Percent) }\end{array}$ \\
1. & $\begin{array}{l}\text { Parents themselves dropout their } \\
\text { children }\end{array}$ & 33 \\
2. & Medium of learning (language) & 20 \\
3. & Failure in examination & 30 \\
4. & Lack of basic facilities in school. & 35 \\
5. & Over loaded syllabus & 28 \\
6. & Cultural and religious beliefs & 35 \\
7. & Early marriage & 30 \\
\hline
\end{tabular}

The above table shows that the most important cause of dropout in primary schools was giving low priority to female education $(33 \%)$. The same factor was considered a major cause of dropout by the teachers. The important cause that was held responsible for dropout by girls was the issue language (20\%). The children belonging to Balch, Sindhi speaking families could not understand Urdu properly and hence leave education incomplete. The other causes of dropout 
considered by the dropped out students (girls) were failure in examination (30\%), lack of basic facilities in schools (35\%), over loaded syllabus (28\%), cultural, and religious beliefs (35\%) and early marriage $(30 \%)$.

\section{Conclusion}

The study explored the causes of high rate of drop out at the primary level of schooling. The views of the teachers, the parents and the girls were gathered to come to know the factors responsible for one of the serious issues of our education system. The basic cause identified by all the respondents was gender discrimination due to which girls cannot continue their education. The other compelling reasons were the issue of language, lack of school facilities, early marriage, cultural and religious beliefs, untrained teachers, corporal punishment, school environment and the over loaded syllabus. It is also evident from the result that gender disparity exits in the area and females are the victims of it.

\section{Recommendations}

On the basis of findings, this study suggests some recommendations for the improvement of girls' education in the province

Medium of education (language) is a basic cause of dropout. Education should be imparted in language which children speak at homes.

Parents must realize the fact that investment in girls' education is not the waste of money.

Cultural beliefs that constrain girls from getting education should be discouraged.

In order to address poverty- education issue, the government, NGOS and public sector must take practical measures. 
Accessibility to school must be increased in rural areas so that parents, without worrying about the security of girls, could send their girls to nearby schools.

There must be free and compulsory education up to the secondary level of schooling. Corporal punishment must be banned in schools.

Teachers must be given proper training in order to improve the quality of education. Communication between parents and teachers must be improved in order to solve the issues of school dropout. 


\section{References.}

Baluch,M. and Shahid,S. 2009, 'Measuring gender disparity at primary school level in Pakistan' , International NGO Journal, Vol. 4, no. 5, pp. 180-189.

Bilqees,F. and Saqib, N.U. 2004, 'Drop-out rates and inter-school movements:

Evidence from penal data', Pakistan institute of Development, Islamabad, Pakistan.

Department of international development (2005).Millennium Development Goal 2: Achieve Universalization of Primary Education. [Online] Available; http//www,dfid.gov.uk/mdg/education.asp (December 2, 2015)

Malik, Zm.2002, 'Causes of dropout in primary schools: a study of primary schools of Sargodha

Tehsil during the years, 1996-97 \& 19997-98', Pakistan Journal of Applied Sciences, vol.2, no.6, pp. 646-648. 